\title{
INVOLUNTARY MOVEMENTS
}

\section{STIMULANTS AND FIRST-ONSET TICS WITH ADHD}

A meta-analysis of studies concerning first-onset tics in children with attention deficit hyperactivity disorder (ADHD) treated with stimulants is reported from the University of Goettingen, Germany. Eleven double-blind, placebo-controlled studies were evaluated, and percentages of first-onset tics during placebo compared to stimulant therapy were calculated and compared, using data from 8 studies. The frequency of tics with placebo varied from 0 to $16.7 \%$ (mean $4.2 \%$ ), and with methylphenidate (MPH) from 0 to $19.6 \%$ (mean $4.3 \%$ ). The delay between starting stimulant medication and tic onset varied from days to weeks, months, or 1 year. A single longer-term (1 year) follow-up double-blind study found the risk of firstonset tics was $20 \%$ during MPH vs $17 \%$ with placebo (difference not significant); $40 \%$ of the tics developed after 4 months or more of treatment. No correlation was observed between the onset of tics and the dose of stimulant, nor the type of stimulant, immediate or extended release, methylphenidate or amphetamine. Most groups with tics were younger than those without. A positive family history had no influence on the emergence of tics during stimulant therapy. The authors conclude that the potential impact of stimulants for ADHD on the development of tics is negligible or of short duration, and a direct causal relationship is seen only in a small minority of affected children. An early triggering of otherwise later spontaneous onset of tics is suggested, rather than stimulant-induced tics that otherwise would not have occurred. (Roessner V, Robatzek M, Knapp G, Banaschewski T, Rothenberger A. First-onset tics in patients with attention-deficit-hyperactivity disorder: impact of stimulants. Dev Med Child Neurol July 2006;48:616-621). (Respond: Veit Roessner MD, Department of Child and Adolecent Psychiatry, University of Goettingen, Von-Siebold-Strasse 5, 37075 Goettingen, Germany).

COMMENT. Tic disorders are reported in about $20 \%$ of children with ADHD. Several reports of stimulant-induced tics and Tourette syndrome (TS) in children with ADHD have appeared in the literature since that of Denckla MB et al. (JAMA 1976;235:1349-51), who cited a risk estimate of $10 \%$. This was followed by a report of Golden GS. (Ann Neurol 1977;2:69-70), citing a risk of 53\% and a relation to dose. More recently, a relationship between the onset of tics and stimulant treatment has been questioned. The common remission and relapsing of tics is a confounding factor in determining cause and relationship to treatment. Of interest, before the $1960 \mathrm{~s}$ and the introduction of stimulants for $\mathrm{ADHD}$, reference to tics or TS in textbooks of neurology was lacking (Wilson, 1955) or restricted to encephalitis lethargica (Ford, 1960) or psychiatric problems (Merritt, 1963). The increased use of stimulants in the US coincides with the recognition of TS by neurologists and a plethora of reports since the 1970s (Millichap JG. J Roy Soc Med 1999;92:156). Pending further long-term controlled studies with evidence to the contrary, I prefer to rely on experience and a cautious approach, withholding stimulants in children with a history of tics or familial susceptibility, and substituting a non-stimulant, atomoxetine (Strattera), when medication for ADHD is essential. 